Vol. 8, n² | 2004

Varia

\title{
Briser la guillotine. Une amnistie thermidorienne
}

\section{Bronislaw Baczko}

\section{CpenEdition}

Journals

Édition électronique

URL : https://journals.openedition.org/chs/458

DOI : $10.4000 /$ chs.458

ISSN : 1663-4837

Éditeur

Librairie Droz

Édition imprimée

Date de publication : 1 novembre 2004

Pagination : $5-31$

ISBN : 2-600-00803-5

ISSN : $1422-0857$

Référence électronique

Bronislaw Baczko, «Briser la guillotine. Une amnistie thermidorienne », Crime, Histoire \& Sociétés / Crime, History \& Societies [En ligne], Vol. 8, n² | 2004, mis en ligne le 26 février 2009, consulté le 23 mars 2022. URL : http://journals.openedition.org/chs/458 ; DOI : https://doi.org/10.4000/chs.458

Ce document a été généré automatiquement le 23 mars 2022

(C) Droz 


\title{
Briser la guillotine. Une amnistie thermidorienne
}

\author{
Bronislaw Baczko
}

Le 26 octobre 1795 (4 brumaire an IV), la Convention nationale proclame l'amnistie pour les «faits purement relatifs à la révolution». Acte solennel par lequel la Convention achève sa mission, cette amnistie politique se présente sous un triple aspect: d'une part, elle est l'aboutissement d'un projet politique, celui de terminer la Révolution; d'autre part, elle est le produit des circonstances, en particulier, de l'écrasement de l'insurrection parisienne encadrée par les royalistes (5 octobre, 1795; 13 vendémiaire, an IV). Finalement, elle est l'œuvre d'un homme, Pierre-Claude-Louis Baudin, conventionnel, député des Ardennes.

\section{I}

2 En juin-juillet 1795, le problème clé de la période thermidorienne : comment sortir de la Terreur, se prolonge par la question : comment terminer la Révolution. Dans une situation très difficile, malgré la guerre sur les frontières et les troubles dans l'Ouest, notamment en Vendée, la Convention prend la décision courageuse d'élaborer une nouvelle constitution et de la mettre immédiatement en activité, de passer donc d'un gouvernement révolutionnaire à un régime constitutionnel, de la Convention réunissant tous les pouvoirs : constituant, législatif et exécutif, à un système basé sur la division et l'équilibre des pouvoirs, bref, de passer d'un régime provisoire et des lois d'exception à un État de droit, stable et durable. Politiquement et institutionnellement l'entreprise était d'autant plus délicate qu'une nouvelle constitution ne pouvait prendre le relais d'une constitution antérieure, mais devait succéder à trois ans de vide constitutionnel. En effet, la constitution de 1791, établissant une monarchie constitutionnelle, a été balayée par la chute de la monarchie, le 10 août 1792; lui a succédé la constitution montagnarde de 1793 qui pourtant n'a jamais été mise en activité. Enfermée solennellement dans une "arche » (un sarcophage, disaient les mauvaises langues), lors de la fête du 10 août 1793, elle a été suspendue jusqu'à la paix 
générale, donc pour une durée indéterminée. Suite aux journées de prairial an III (20-22 mai1795), dernier sursaut de ce qui en restait de la sans-culotterie parisienne et du mouvement jacobin (on se souvient, que les insurgés ont alors revendiqué la constitution de 1793), la Convention thermidorienne a définitivement abandonné l'idée de remanier la constitution montagnarde. Très rapidement, elle a chargé une commission des Onze d'élaborer le projet d'une nouvelle constitution ainsi que de proposer les mesures de sa mise immédiate en activité. La Convention a commencé à débattre le projet le 25 juin ( 5 messidor), et, deux mois plus tard, elle a adopté la nouvelle loi fondamentale.

3 En 1793, la Constitution montagnarde avait été entérinée par une votation populaire. Les conditions de ce scrutin étaient parfois douteuses et ses irrégularités assez notoires, toutefois c'était un précédent incontournable. Pour assurer la légitimité à la nouvelle constitution il fallait à son tour la soumettre à l'acceptation populaire; il fallait, ensuite, mettre sur pied les nouvelles institutions, notamment un nouveau corps législatif et un nouveau pouvoir exécutif. Comment pourtant passer sans nouvelles secousses d'un régime révolutionnaire à un ordre constitutionnel ? Comment assurer la transition de l'un à l'autre, marquer une rupture tout en assurant la continuité ? Les thermidoriens sont pris dans ces contradictions, un véritable casse-tête politique et constitutionnel. Quelle que soit la perfection de la nouvelle constitution, le passage d'un régime à l'autre est perçu comme le moment de tous les dangers. Par définition, toute institution nouvelle est fragile; le nouveau régime constitutionnel sera d'autant plus vulnérable, que le pays est toujours en guerre et la République court toujours un double danger, celui de la restauration de la monarchie, comme celui du retour de la Terreur. Pour consolider le nouveau régime, il faut donc donner du temps au temps, et, pour réussir le changement institutionnel, il faut garantir la continuité de la politique thermidorienne. Rupture et continuité, innovation et conservation, ces questions resteraient plus ou moins abstraites, si elles ne se doublaient pas d'une autre préoccupation, combien concrète et lancinante : la révolution terminée, quels lendemains attendent ceux qui l'ont amenée au bon port? ou, pour le dire plus crûment : après la Convention, quel avenir pour les conventionnels? Après maintes tergiversations la commission des Onze élabore les dispositions censées répondre à ces difficultés : la nouvelle constitution sera soumise à l'approbation du peuple; à la même occasion les assemblées primaires se prononceront sur les décrets stipulant l'obligation de reconduire deux tiers d'anciens conventionnels, par le truchement d'une procédure électorale très complexe à deux degrés, au nouveau corps législatif (donc choisir obligatoirement 500 conventionnels sur les 750 députés formant les futurs deux Conseils, le Conseil des Cinq Cents et le Conseil des Anciens). Ce n'est que plus tard, par tiers et lors de deux élections annuelles successives, que les anciens conventionnels seront à leur tour renouvelés. Ainsi les nouvelles institutions représentatives seraient en majorité investies par l'ancien personnel au pouvoir; elles perpétueront sinon la Convention, alors la majorité des conventionnels. Chargé de ce dossier par la commission des Onze dont il était membre, Baudin présenta les décrets respectifs (appelés couramment décrets des deux tiers et assimilés aux articles constitutionnels) dans deux importants discours politiques: le rapport sur les Moyens de terminer la Révolution (18 août, $1^{\text {er }}$ fructidor), et un autre portant sur les modalités du système électoral (30 août, 13 fructidor). D'où aussi le calendrier de ces opérations compliquées, très serré, car la Convention décide d'aller vite, d'écourter la période d'incertitude et, partant, de prendre de vitesse les adversaires des décrets des deux tiers. Tout devait être bouclé en deux mois: le 6 
septembre (20 fructidor), réunion des assemblées primaires et référendum sur la constitution ainsi que sur les décrets des deux tiers; le 12 octobre (20 vendémiaire an IV), réunion des assemblées de second degré et élection des députés au nouveau corps législatif; début novembre, séparation de la Convention (suivie, le cas échéant par la cooptation des conventionnels manquant au quota des cinq cents), réunion du nouveau corps législatif et élection du nouveau pouvoir exécutif, le Directoire.

La Révolution terminée, les passions révolutionnaires retombées, les nouvelles institutions installées, sur l'horizon d'attentes la commission des Onze fait également pointer l'idée d'une amnistie politique. Acte symbolique fort mais aussi une mesure politique indispensable car les prisons thermidoriennes regorgent de détenus. En effet, l'amnistie devrait tourner une double page, celle de la Terreur et celle de la répression anti-terroriste. Après le 9 thermidor, la Convention lance la politique qui se réclame du mot d'ordre la justice à l'ordre du jour, politique qui se traduit d'abord par la libération rapide, sans grandes formalités, des milliers de prisonniers politiques. Elle se traduit également par les grands procès politiques qui dévoilent l'arbitraire et l'horreur de la Terreur : le procès de Carrier qui était aussi celui de la répression en Vendée; le procès de Fouquier-Tinville et ses coaccusés qui a montré les coulisses lugubres du Tribunal révolutionnaire; la procédure contre Joseph Lebon qui démasque l'arbitraire tyrannique d'un représentant en mission. La politique de justice à l'ordre du jour entraîne une masse de dénonciations contre le personnel politique et administrative de la Terreur, un défoulement collectif animé par les passions vindicatives contre les petits «terroristes ». Deux décrets de la Convention sanctionnent une politique de répression anti-terroriste : une loi (du 23 février 1795, 5 ventôse an III) assigne les « terroristes » à résidence dans les lieux où ils ont exercé leurs fonctions pendant la Terreur, et, partant les livre à la vindicte de leurs ennemis; une autre loi (du 10 avril 1795, 21 germinal an III) impose leur désarmement et, partant, les désignent comme victimes potentielles de cette vindicte. Sur simple dénonciation, sans vérifications des accusations, les membres des comités révolutionnaires, les jurés des tribunaux révolutionnaires, les militants jacobins, les fonctionnaires locaux, agents et auxiliaires de la Terreur, coupables d'avoir exercé, à l'époque, une parcelle du pouvoir, se retrouvent en prison en attente d'une justice incertaine, et débordée, inefficace et partisane. La justice est lente, tandis que les passions revanchardes sont violentes et impatientes. À Lyon et en Avignon, à Tarascon et à Marseille, dans tout le Midi, ont lieu des massacres : des bandes armées se font justice et procèdent au lynchage des "terroristes" dans les prisons ou lors du transfert des détenus. Ces massacres se font parfois avec l'assentiment tacite des autorités locales et avec l'approbation d'une importante partie de la population. Selon les estimations fort incertaines de l'époque, une vingtaine de milliers de "terroristes " se trouveraient dans les prisons thermidoriennes. Pour fuir la vindicte, un nombre important de « terroristes » quittent leur domicile et cherchent refuge dans les grandes villes, notamment à Paris. C'est aussi à Paris que se retrouvent de nombreux militaires sans affectation, plus ou moins suspects de jacobinisme. Comment donc terminer la Révolution avec cette lourde hypothèque, des milliers de personnes en attente de jugement d'une équité douteuse ? L'autre dossier qui demande d'urgence une réponse : les centaines de milliers de personnes inscrites sur la liste des émigrés. Après thermidor, profitant du relâchement du pouvoir, nombreux sont ceux qui sont rentrés en France, plus ou moins illégalement, et qui se trouvent dans une situation irrégulière, donc passables de très lourdes peines. L'exil était une plaie ouverte, un douloureux rappel des convulsions révolutionnaires. 
5 Les mesures pour terminer la révolution impliquent donc une amnistie politique dont la commission des Onze charge Baudin d'élaborer le projet. Le précédent a été d'ailleurs créé par la Constituante qui, le 14 septembre 1791, après l'acceptation de la constitution par le roi, a décrété une amnistie aux personnes poursuivies pour des activités ayant trait à la révolution. Par ailleurs, le 2 décembre 1794, la Convention ellemême a déjà décrété une amnistie aux insurgés de la Vendée acceptant de déposer les armes.

\section{II}

6 L'idée de consacrer la fin de la Révolution par une amnistie se concrétisera sous l'impact de la « journée » du 13 vendémiaire, de l'écrasement de l'insurrection royaliste parisienne. Les conséquences politiques de cet événement majeur et imprévu ont singulièrement compliqué l'affaire d'amnistie projetée et ont grandement influencé ses formes et sa portée.

7 Le sanglant affrontement du 13 vendémiaire an IV (5 octobre 1795) est le dénouement du conflit qui oppose les sections parisiennes modérées à la Convention et à ses comités de gouvernement. Comme nous l'avons observé, la Convention a projeté de mener tambour battant les opérations relatives à la mise en activité de la nouvelle constitution, commençant par la convocation des assemblées primaires et le lancement du référendum sur la constitution et les décrets des deux tiers. Or, dès l'annonce de ces décrets, elle butte sur une forte opposition. Une campagne de contestation et de dénigrement est déclenchée par la presse modérée ou crypto-royaliste qui, à cette époque, jouit d'une réelle liberté, comparable à celle qu'elle avait connue dans les années 1789-1791. La majorité des conventionnels sont violemment pris a partie; on leur reproche, d'être lourdement responsables de la Terreur : pendant dix-huit mois les uns ont activement soutenu la tyrannie de Robespierre, tandis que d'autres, par lâcheté ou par opportunisme, l'ont tolérée. Or, le décret des deux tiers n'est qu'une machination de ces conventionnels qui veulent se "perpétuer»: ils craignent les élections et s'accrochent au pouvoir dont ils ne sont guère dignes. Les opposants inventent une habile tactique politique : ils appellent les assemblées primaires à séparer les deux objets du plébiscite que la Convention voulait faire voter conjointement, à savoir à accepter la constitution maisà rejeter les décrets des deux tiers. Cette tactique trouve rapidement un large appui dans la plupart des sections parisiennes. Face à cette fronde, pour mieux se positionner dans le conflit avec les sections, la Convention décrète que les " terroristes ", même s'ils sont assignés à résidence ou désarmés, n'ont pas pourtant perdu leur droits civiques et ont donc le droit de participer aux assemblées primaires et, le cas échéant, d'être désignés comme électeurs. Tout se passe donc comme si, la veille de la convocation des assemblées primaires, le pouvoir thermidorien envisageait le revirement de sa politique répressive, comme s'il s'apprêtait à faire bon usage des « terroristes » et s'inventait ainsi une armée de réserve.

8 Une riposte des sections parisiennes au retour des « terroristes » à la vie publique était prévisible et ne s'est pas faite attendre. Lors de l'ouverture des assemblées primaires (6 septembre, 20 fructidor), seize sections parisiennes ont souverainement décidé d'expulser sur le champ les "terroristes ", c'est-à-dire les citoyens désarmés mais inscrits sur les rôles électoraux, comme personnes indignes d'exercer des droits civiques. Expulsions donc parfaitement illégales qui marquent le point de non-retour 
du conflit. Dès le premier jour de leurs délibérations, les assemblées frondeuses communiquent entre elles, activité interdite par la loi, s'envoient mutuellement des proclamations et des commissaires, s'accordent une mutuelle garantie et, surtout, se déclarent permanentes et souveraines, agissantes au nom du peuple qui reprendrait ainsi la plénitude de son pouvoir. Dès le premier jour, il est également question de former un Comité central de sections rebelles, un organe directeur unique, amorce d'un véritable contre-gouvernement. L'originalité de cette tactique, ainsi que du discours qui l'orchestre, réside dans une remarquable opération d'acculturation politique. En effet, les sections en rébellion empruntent leur langage et leur tactique aux "journées » révolutionnaires jacobines: reprise par le peuple de sa souveraineté; démocratie directe opposée à la représentation parlementaire usurpatrice; les gouvernés, le peuple parisien, mobilisés contre les gouvernants qui les ont trahis; les assemblées primaires organisées en réseau analogue à celui formé par les sociétés patriotiques. Le refus de gouvernants et la stratégie de la confrontation font office de leur programme politique qui n'est défini que négativement, contre les "perpétuels » et contre le retour des «terroristes ». Les meneurs des sections les plus actives et les plus radicales sont des royalistes convaincus, qui s'approprient le langage démocratique et révolutionnaire et, cyniquement, le manipulent; dans ce sens, tout le mouvement est encadré par des royalistes, notamment par des jeunes journalistes, tels Lacrettelle-jeune, ou RicherSerizy. Cependant, ils n'affichent pas ouvertement leur couleur et à aucun moment ces meneurs n'ont arboré le drapeau blanc; nulle déclaration politique des sections ne fait appel à Louis XVIII, ni à un autre prétendant. Ainsi la rébellion est sans cesse flétrie comme royaliste par ses adversaires mais elle ne revendique jamais cette couleur politique pour elle-même. Autant qu'ils soient explicités, les objectifs du mouvement consisteraient à en découdre avec les terroristes et leurs protecteurs, une fois pour toutes, et à se débarrasser des « perpétuels ». L'absence d'un programme positif fait à la fois la force et la faiblesse du mouvement parisien. La force, dans la mesure où cela permet d'embrasser largement, de fédérer les peurs, les frondes et les mécontentements ainsi que de réserver une bonne part à la spontanéité et à l'improvisation. Sa faiblesse également, dans la mesure où l'absence de programme positif, les silences et les sous-entendus, font surgir des doutes et des méfiances chez tous ceux qui, dans les sections, hésitent à franchir les limites entre une escalade verbale et un affrontement violent, entre une grogne contre les gouvernants et une insurrection armée contre le gouvernement républicain. Face au pouvoir républicain et à ses ressources, notamment à ses forces armées, le mouvement parisien était-il une aventure politique, d'avance condamnée à l'échec? Sur ce point, les meneurs ont également bien assimilé les leçons de l'expérience révolutionnaire: les "journées » révolutionnaires n'ont-elle pas démontré qu'à condition d'être audacieux, bien organisé et appuyé par la masse populaire, un coup hasardeux peut parfaitement réussir? Ni politiquement, ni même militairement, la rébellion n'était guère une cause désespérée. Les meneurs pariaient sur la dynamique propre du mouvement, sur l'effet de boule de neige qui entraînerait une très large population parisienne, en particulier la garde nationale; par ailleurs, le mouvement pouvait compter sur des complicités au sein même de la Convention, de la part des adversaires des décrets des deux tiers. En outre, au cas de rejet de ces décrets par le référendum, la Convention se trouverait non seulement désavouée mais aussi privée de toute légitimité. Les meneurs pouvaient également compter sur des complicités au sein de l'armée, des troupes de ligne 
stationnées aux portes de Paris, ainsi que sur la réticence de la troupe devant un combat fratricide.

9 À ces défis la Convention réagit assez mollement. Elle se contente de condamner les sections rebelles et de déclarer illégales leurs agissements, en particulier leur prétention à incarner le peuple souverain ainsi que l'expulsion des «terroristes » des assemblées primaires. Elle admet à la barre une délégation des expulsés qui se sont présentés comme des citoyens lésés, «patriotes de 89 » injustement persécutés sous la dénomination des «terroristes ». Naturellement, nul n'est dupe que ces «patriotes de 89 ", auxquels on a même accordé les honneurs de la séance, traînent derrière eux un passé révolutionnaire sulfureux. Depuis cet accueil, dans le langage officiel, la dénomination "patriotes de 89 » fonctionne comme un terme codé, voire comme un mot de passe. Aux autorités, ce terme permet de grouper autour de lui des ressources humaines non négligeables, sans pourtant se compromettre et sans remettre en question sa propre législation anti-terroriste. À leur tour, les «terroristes » réprimés s'en servent comme d'un signe de ralliement qui les soustrait aux persécutions et constitue un gage de leur sécurité. La Convention a également interdit la communication entre les assemblées primaires, interdiction qui n'a été suivie d'aucun effet. Les deux camps restent mobilisés, mais tout est suspendu aux résultats de la votation sur la constitution et les décrets des deux tiers : à la Convention on s'attend à une nette victoire qui désamorcerait la crise, tandis que dans les sections on espère un franc désaveu de gouvernants, tout en redoutant la fraude électorale.

10 Finalement, le 28 septembre (6 vendémiaire an IV) ont été publiés les résultats : la constitution a été acceptée par 1057368 votants, et rejetée par 49 978, les décrets des deux tiers ont recueilli 205282 oui et ont été rejetés par 108784 voix ${ }^{2}$. Ce dernier chiffre était particulièrement décevant pour la Convention : un tiers des votes pris en compte refusa les décrets contestés, et cela malgré les machinations électorales qui avaient soustrait ceux-ci aux suffrages de la plupart des électeurs (d'où l'énorme disparité entre le nombre respectif de votants qui se sont prononcés sur l'un ou l'autre objet du référendum). En outre, sous prétexte de vice de forme, les votes de 120 assemblées primaires ne furent pas pris en compte; or, comme par hasard, ces assemblées avaient voté contre les décrets. À Paris même, pour la Convention, les résultats étaient catastrophiques : sur 48 sections, une seule accepta les décrets des deux tiers, à savoir celle des Quinze-Vingts dont faisait partie le faubourg SaintAntoine. Toutefois, les votes de 33 sections n'avaient pas été pris en compte sous prétexte que leurs procès-verbaux constataient le rejet à l'unanimité, sans indication du nombre de votants... La Convention ne pouvait donc compter que sur une seule section. En outre, celle-ci ne comportait presque plus de gardes nationaux car ils étaient frappés par les mesures de désarmement des «terroristes"; par contre, la garde nationale armée se retrouvait dans les sections franchement hostiles à la Convention, ou, dans le meilleur des cas, fort hésitantes. Rapport de suffrages donc, mais aussi rapport de forces: les résultats du vote apportent la démonstration flagrante que la ville échappe au contrôle du pouvoir central.

11 Dans les sections, la publication de ces résultats suscite un tollé : les esprits s'échauffent, on crie à la fraude, on refuse de reconnaitre les résultats officiels; certaines sections remettent en prison des "terroristes " libérés par le Comité de sûreté générale. La Convention appelle la ville rebelle au calme, menace de se retirer à Chalons, si sa sécurité n'est pas assurée; le 25 septembre ( ${ }^{3}$ vendémiaire), elle fait 
investir Paris par les troupes de ligne. Elle alerte également les "patriotes de 89 ", à savoir des citoyens désarmés, des détenus dans les prisons parisiennes, des officiers, relégués ou sans emploi, etc. Passant outre les décrets et les interdictions de la Convention, les sections parisiennes ne cessent d'échanger de nouvelles délégations et de voter des motions incendiaires. Le 2 octobre (11 vendémiaire), les sections franchissent un pas de plus dans l'escalade des menaces et des actes illégaux: elles refusent à la Convention toute autre autorité légitime que celle d'expédier les affaires administratives courantes et elles convoquent les électeurs de Paris afin de former une autorité insurrectionnelle, un véritable centre de contre-pouvoir par rapport aux comités de gouvernement. La Convention décrète de lourdes peines contre les meneurs, et, pour prendre de court les organisateurs du coup de force, elle avance de dix jours la convocation du nouveau corps législatif. Ainsi, la dispersion de la Convention est définitivement fixée au 26 octobre ( ${ }^{4}$ brumaire); le lendemain devrait se réunir le corps législatif nouvellement élu. Le 11 vendémiaire ( 3 octobre) la Convention décide finalement de lancer un appel aux volontaires qu'elle invite à se joindre à l'armée; en espace de quelques heures ils s'en présente environ 1500 , qui, le lendemain, ont été formés en trois «bataillons sacrés de patriotes de 89 »; ils ne portent pas d'uniforme, mais on leur distribue des armes et des vivres et on les soumet à un commun commandement avec les troupes de ligne. Toutefois, la plupart de ces «patriotes de 89 ", sinon tous, étaient toujours sous le coup des lois répressives sur le désarmement des "terroristes" ou sur leur assignation à résidence. En formant ces «bataillons sacrés » la Convention se mettait ainsi en flagrante contradiction avec elle-même et, d'après sa propre jurisprudence, la légalité du groupement de ces "patriotes » était fort douteuse. Pour sortir de cet imbroglio et sauver les apparences, la Convention abroge, sur le champ, les lois respectives, abrogation qui est un désaveu tacite de sa politique de répression contre les "terroristes" et sonne comme une promesse d'amnistie. La formation de ces bataillons est perçue par les sections comme une provocation et, en ville, provoque même un début de panique : les «terroristes » sont de retour et se préparent à prendre leur revanche. Pour la Convention, ces bataillons constituent un apport militaire non négligeable, vue la faiblesse numérique des troupes de lignes, environ trois à quatre mille hommes effectivement disponibles.

12 L'affrontement est donc devenu inévitable. Il a lieu le 13 vendémiaire ( ${ }^{5}$ octobre) et est sanglant : environ deux à trois cents morts et blessés du côté des insurgés et presque autant du côté des forces de la Convention. Après le 10 août 1792, c'était la plus meurtrière des «journées" révolutionnaires. Les combats les plus acharnés se sont déroulés dans les rues voisinant la Convention; les soldats et les "patriotes » blessés ont été transportés dans les locaux de l'Assemblée et soignés sur place. Les forces en présence étaient numériquement presque à égalité, notamment grâce à l'appel aux «patriotes de 89 ». L'efficacité du commandement fut un des facteurs déterminant la victoire de la Convention: appelé à assurer le commandement, le jeune général suspecté de jacobinisme a su s'emparer, à temps, des canons; il a habilement disposé les postes assurant la défense de l'enceinte des Tuileries, où siégeaient la Convention et ses Comités de gouvernement, et il a placé l'artillerie aux points stratégiques. Le moment venu, sans états d'âme, Bonaparte a canonné la foule d'insurgés. Redoutable professionnalisme du jeune général mais aussi courage des bataillons improvisés des " patriotes de 89 » qui, dans le combat, retrouvaient leur dignité. Même une vingtaine d'années plus tard, Bonaparte se souviendra toujours de leur détermination et rendra hommage à leur contribution à la victoire. «La Convention, pour accroître ses forces, 
donna des armes à quinze cents individus dits les patriotes de 89. C'étaient des hommes qui, depuis le 9 thermidor, avaient perdu leurs emplois, et quitté leurs départements où ils étaient poursuivis par l'opinion [...]. Ces hommes se sont battus avec la plus grande valeur. Ils entraînaient la troupe et furent beaucoup dans le succès de la journée » ${ }^{3}$.

Au lendemain du 13 vendémiaire, la Convention est confrontée au problème : que faire de sa victoire, terrible et sanglante? Le défi était de taille et le projet même de terminer la révolution était en jeu. Des velléités révolutionnaires et des pressions radicales persistent jusqu'au dernier moment; la gauche, sorte de Montagne recomposée, appelle à agir de manière forte et éventuellement, pour consolider la victoire, à suspendre les élections au corps législatif, tandis que les députés modérés restent fidèles au projet initial ainsi qu'à son calendrier. Finalement, la Convention décide de mener à bon port le processus de la mise en activité de la nouvelle constitution et, donc, de respecter les échéances: le 12 octobre (20 vendémiaire), réunion des assemblées électorales et désignation de nouveaux députés; le 26 octobre (4 brumaire), à treize heures, fin des travaux de la Convention; le lendemain, réunion du nouveau corps législatif.

Les vainqueurs du 13 vendémiaire doivent également apporter une solution rapide à un double problème : que faire des «bataillons sacrés de patriotes de 89 »? Que faire de ces autres anciens terroristes qui croupissaient toujours dans les geôles thermidoriennes? Au moment de la formation de ces bataillons, les autorités ont proclamé que le recours aux "patriotes de 89 », imposé par les circonstances, n'était que momentané et que, dès que la situation le permettrait, ils rentreraient dans leurs foyers. Une députation des " patriotes de 89 ", à la barre de la Convention, a d'ailleurs pris solennellement un engagement analogue. Ainsi, dès le 15 vendémiaire, le licenciement de ces bataillons est envisagé, opération qui s'étale finalement sur quelques jours. Toutefois, la plupart de ces «patriotes" se trouvaient toujours dans une situation irrégulière: on se souvient que, le jour de l'appel aux volontaires, la Convention avait abrogé une partie essentielle de son dispositif juridique antiterroriste, en particulier, les décrets sur leur désarmement et leur assignation à résidence. Cela ne réglait pas pourtant le cas de personnes qui, sous divers prétextes, avaient été emprisonnées et que le Comité de sûreté générale était allé chercher comme volontaires dans les prisons parisiennes; d'autre part, parmi les «patriotes de 89 » nombreux étaient les «terroristes » qui, redoutant l'arrestation, avaient fui leur département d'origine. Comment donc renvoyer dans leurs foyers des «patriotes de 89 » qui, chez eux, toujours sous le coup de poursuites, risquaient de retourner en prison? Le cas de "patriotes de 89 » devait fatalement entraîner la révision de la politique répressive contre tous les «terroristes » incarcérés : en effet, après le 13 vendémiaire il était devenu politiquement et juridiquement intenable de les faire croupir dans les prisons dans l'attente d'une incertaine justice. Ainsi, une semaine après la « journée » du 13 vendémiaire, la Convention adopte le décret qui interdit de traduire devant les tribunaux aucun citoyen qui ne sera prévenu de meurtre, d'assassinat, de vol ou d'un autre crime prévu et spécifié par les lois pénales; il déclare nul tous les actes d'accusation qui ne porteraient pas sur ces derniers cas et, finalement, stipule la mise en liberté sur le champ, dans les 24 heures, sans nul examen préalable, de tout individu contre lequel il n'aurait été dressé que des actes déclarés nuls par ce même décret. C'était donc une amnistie politique qui ne disait pas son nom. Son mérite revient d'abord aux " patriotes de 89 » : leur engagement, leur courage et leur mort ont finalement joué en faveur de tous les « terroristes » incarcérés. Toutefois, 
en ouvrant ainsi largement les portes de prison, la Convention se débarrassait d'une lourde hypothèque : les procédures en attente contre des milliers de "terroristes" auraient pris de longues années et auraient fait revivre les haines d'une révolution que l'on voulait terminer.

Toutefois, les individus impliqués dans la révolte du 13 vendémiaire ont été formellement exclus de ces mesures de clémence. En effet, sur le coup des événements, la Convention a décidé de prendre des mesures énergiques pour pacifier la ville et punir les coupables. La garde nationale est désarmée, sans d'ailleurs présenter nulle résistance; son état-major supprimé, elle passe sous l'autorité du commandant militaire de la place de Paris, subordonné au chef de l'armée de l'Intérieur, poste auquel est nommé Bonaparte. Les Comités de gouvernement ont fait venir des renforts, et Paris, occupé militairement, rappelle une place de guerre. La troupe campe dans le jardin des Tuileries, sur les places publiques et aux portes de la ville; elle patrouille les rues et assure la police. Les soldats se comportent parfois comme dans une ville conquise; il y a eu quelques maraudages mais, contrairement aux craintes et rumeurs persistantes, nul pillage systématique. Le 7 octobre (15 vendémiaire), la Convention décrète la formation de trois commissions militaires qui, en l'espace de dix jours, ont à juger les auteurs et les principaux instigateurs de «la conspiration et de la rébellion du 13 vendémiaire ", les individus qui ont " excité les citoyens à s'armer et à marcher contre la Convention ", l'état-major des rebelles, etc. Après les combats, des centaines de rebelles armés ont été arrêtés; rapidement, en espace de quelques jours, le Comité de sûreté générale, après avoir reconnu qu'ils n'étaient que des "gens égarés ", en a relâché la plupart. Les trois commissions militaires ont prononcé 49 condamnations à mort, dont seulement deux ont été exécutées. Tous les autres instigateurs de la rébellion ont été jugés par contumace, et pour cause : la plupart ont réussi à fuir Paris sans aucune difficulté, d'autres se cachent en ville, sans être trop inquiétés. Indulgences qui résulteraient des connivences avec les meneurs? Peut-être, mais surtout conséquence d'un choix politique capital : avant toute autre considération, que ce soit la répression légitime ou l'exigence de justice, faire passer l'objectif politique majeur, à savoir la fin du gouvernement révolutionnaire et l'instauration de l'ordre constitutionnel. Décrétée à chaud, la loi sur les commissions militaires déclare passibles de la peine capitale plusieurs centaines de personnes gravement impliquées dans la rébellion. Or, appliquée à la lettre et avec sévérité, elle aurait compromis le processus constitutionnel engagé. Comment, en effet, dans le sillage de nouvelles charrettes et dans l'ombre de la guillotine dressée en permanence, renoncer aux méthodes révolutionnaires, procéder aux élections et mettre en activité la nouvelle constitution?

16 Cependant, une fois le nouveau régime constitutionnel mis en place, comment faire pour qu'un nouveau 13 vendémiaire ne se reproduise pas ? Comment empêcher que la " contre-révolution ne se fasse pas constitutionnellement ", comme mettait en garde un député ? Au fur et à mesure que, après le 12 octobre ( 20 vendémiaire), commencent à parvenir les résultats des élections au nouveau corps législatif, ces préoccupations deviennent pressantes et agitent surtout la gauche de la Convention. Force est de constater que les électeurs ont porté leur choix sur des candidats modérés, voire sur des candidats ayant une réputation royaliste ou même sur des personnes compromises par leur implication dans l'insurrection du 13 vendémiaire. Ainsi assiste-t-on au sursaut de dernière heure des députés radicaux de gauche qui exigent l'adoption de " grandes mesures ». À la Convention on complote jusqu'à la chute du rideau. Quatre jours avant la date limite, sous prétexte que les assemblées électorales étaient infectées par des 
contre-révolutionnaires et que la victoire du 13 vendémiaire a été galvaudée puisque les meneurs ne sont punis que sur le papier, quelques députés influents s'efforcent encore de monter un coup, de concocter une majorité de circonstances qui casserait les élections et, partant, bloquerait le processus constitutionnel. Cette machination est déjouée mais la crainte que la fin promise de la Révolution pourrait entraîner le début de la fin de la république, trouble les esprits. Finalement, pour les calmer, la veille de la fin de son mandat, la Convention décrète un train de mesures préventives, d'exclusion et de répression.

17 Adoptée le 25 octobre ( 3 brumaire) la loi frappe cinq catégories de personnes: les individus compromis dans la rébellion du 13 vendémiaire; les émigrés, les royalistes, les prêtres réfractaires, les familles des émigrés. Ainsi les personnes, qui dans les assemblées primaires ou dans les assemblées électorales, ont signé ou provoqué des mesures contraires à la loi, ne pourront, jusqu'à la paix générale, exercer nulle fonction publique; la même mesure d'exclusion de fonctions publiques frappe les émigrés qui n'ont pas obtenu leur radiation ainsi que leurs parents, jusqu'au troisième degré, méticuleusement spécifié : père, fils, frères, beaux-frères, oncles, neveux, etc. Toute personne qui se trouve dans les cas désignés, et aurait accepté une fonction publique, devrait s'en démettre dans les vingt-quatre heures; les contrevenants seront lourdement punis. Vient ensuite une incitation à l'« auto-bannissement " adressée à " tous ceux qui ne voudraient pas vivre sous les lois de la république et s'y conformer ", notamment aux royalistes : ils sont autorisés, dans les trois mois, à quitter le territoire français, en conservant cependant une partie de leur fortune. Ceux qui se seront ainsi bannis volontairement ne pourront plus jamais rentrer en France; s'ils rentraient, ils seraient considérés comme des émigrés, et seraient donc passibles de lourdes peines, allant jusqu'à la peine capitale. Un article spécial concerne les femmes des émigrés : même divorcées mais non remariées, elles sont tenues de se retirer dans leur domicile habituel où elles sont assignées à résidence; la même mesure s'applique à leur parenté, jusqu'au troisième degré, de nouveau méticuleusement énumérée. Les prêtres sujets à la déportation ou à la réclusion seront arrêtés dans les 24 heures. Tous les contrevenants à la loi sont passibles de lourdes peines : bannissement à perpétuité, vingt ans de fer, etc. C'était donc un train de très graves mesures répressives; la loi devait constituer un gage contre les mauvaises surprises politiques de la postrévolution et, dans l'avenir, conjurer l'éventualité d'une déconfiture électorale des gouvernants. Au delà de la fin annoncée de la révolution, elle prolonge le provisoire révolutionnaire, ses mesures d'urgence et d'exception, et préfigure les coups d'État du Directoire. La loi du 3 brumaire s'inscrit ainsi dans la logique d'exclusion et de soupçon qui marque profondément la culture politique révolutionnaire. Décréter la révolution terminée était une chose, se séparer du passé révolutionnaire en était une autre. Ainsi, après le 13 vendémiaire, en l'espace des vingt derniers jours de son parcours, d'une part, la Convention, a ouvert les portes des prisons et, d'autre part, elle a décrété de nouvelles mesures de répression et d'exclusion. L'amnistie qu'elle proclame comme son dernier acte se ressent fatalement des ambiguïtés et des contradictions de cette période confuse. 
Le 3 brumaire, lors de la même séance où elle vote sa dernière loi répressive, la Convention entame l'examen du rapport sur l'amnistie. Le rapporteur, P. J.L. Baudin présente le projet au nom de la commission des Onze qui a élaboré la nouvelle constitution ainsi que les mesures pour terminer la révolution, donc au nom d'une instance dont les responsabilités font valoir le caractère solennel de son intervention ainsi que de l'acte proposé. En effet, depuis le lancement du processus constitutionnel, la commission des Onze a conçu l'amnistie comme son point d'orgue, l'acte ultime clôturant la mission de la Convention et consacrant la fin de la révolution. Son choix de rapporteur n'est pas dû au hasard : élu le 6 mai (17 floréal) membre de la commission des Onze, Baudin se voit confier la tâche difficile de faire approuver par la Convention les mesures liées à la mise en activité de la nouvelle constitution. Ainsi, ce conventionnel, jusqu'alors plutôt effacé, se trouve propulsé sur l'avant-scène politique et à l'été-automne 1795 , lors des dernières semaines de la Convention, joue un rôle de premier plan. Le 18 août (1 fructidor), au nom de la commission des Onze, il présente son rapport sur les Moyens de terminer la révolution qui, après quatre jours de houleux débats dans lesquels Baudin intervient énergiquement, débouche sur l'adoption du décret des deux tiers. Deux semaines plus tard, sur la base de son nouveau rapport, la Convention règle le mode de réélection obligatoire de deux tiers des conventionnels. Ces discours de Baudin sont des textes remarquables. Ses arguments à l'appui des projets de loi sont nourris d'une réflexion sur les chemins sinueux parcourus par la Révolution, en particulier sur la Terreur et sur la période thermidorienne. Il fait partie de ces thermidoriens qui sont sortis de la Terreur enrichis d'une âpre expérience politique, plus riches également en connaissances de la nature humaine, fatalement pas trop optimistes. Ses discours se distinguent par un regard lucide et désenchanté, très thermidorien, sur la politique révolutionnaire, voire sur la politique tout court. Baudin est un thermidorien, et il est fier de l'être. Il considère la période thermidorienne comme le moment culminant où la nation arrive, enfin, à sa maturité et où, enfin, la révolution touche au terme de son dramatique parcours. Ses discours offrent ainsi un commentaire intéressant sur toute cette période mouvementée et, en particulier, sur les raisons et les événements qui amènent la Convention à penser la fin de la Révolution en termes d'oubli ${ }^{4}$. Rendant hommage à ses mérites la Convention l'a élu son président, du $1^{\mathrm{er}}$ au 15 vendémiaire an IV, période de tous les dangers. À ce titre, le 12 vendémiaire (4 octobre), lors d'une séance solennelle commémorant les députés exécutés pendant la Terreur, Baudin prononce un très remarquable discours; le même jour, il accueille à la barre de la Convention une députation des bataillons de terroristes convertis en "patriotes de 89 ». Pendant toute cette période critique, en sa qualité de président de la Convention, Baudin se distingue par son énergie, sa fermeté et son habilité politique. Finalement, le 3 brumaire ( 25 octobre), il lui revient l'honneur de présenter le rapport sur l'amnistie, acte hautement symbolique, dernière mesure marquant la fin de la Révolution. Baudin a commencé à rédiger son rapport longtemps à l'avance; une partie de son texte date sûrement de l'époque d'avant la «journée » du 13 vendémiaire; par la suite, en fonction de nouvelles circonstances politiques, le tout a été remanié. Baudin s'attendait à ce que la Convention consacre une séance solennelle à son rapport et au projet de loi d'amnistie. Il se trouva pourtant dépassé par les événements dont l'accélération chaotique a bousculé le scénario espéré. Dans son texte Baudin prolonge sa réflexion sur les rapports entre politique et morale, amorcée dans 
son précédent discours sur les Moyens de terminer la Révolution. Il fait entendre une sagesse bien thermidorienne, un réalisme nourri d'expériences amères, mélange de désenchantement et de ce qui en reste encore de l'enthousiasme révolutionnaire. Texte injustement oublié, que nous reproduisons ci-dessous, in extenso. Contentons-nous d'insister ici sur trois idées fortes de ce rapport: personne ne sort infaillible d'une grande révolution; la justice ne peut plus réparer certains maux qui en sont inséparables; acte juste et nécessaire, l'abolition de la peine capitale est à la fois l'emblème de la révolution terminée et le présage d'un avenir post-révolutionnaire meilleur ${ }^{5}$.

D'emblée Baudin inscrit l'amnistie dans les cadres d'un projet politique global. « Elle (la commission des Onze) doit à la Convention, elle doit à la République de déclarer solennellement qu'elle ne croit point la Révolution terminée sans une amnistie (...) En vous remettant nos pouvoirs, le dernier usage que nous allons en faire, est de nous acquitter de ce que nous prescrit notre conscience; c'est elle qui nous pressa de travailler au plan d'une véritable constitution; c'est elle encore qui nous oblige de vous dire qu'aucun gouvernement ne s'établit sans l'oubli des fautes et des erreurs qui ont précédé et même troublé ou retardé sa formation ». Nécessaire, l'amnistie doit porter sur des actes spécifiques; elle doit effacer « les souvenirs des erreurs et des fautes qui ont été commises pendant la Révolution». D'une grande et orageuse révolution personne ne sort innocent, sans failles et sans erreurs. "Qu'il s'avance cet homme privilégié, citoyen ou magistrat, ou représentant du peuple, qui pourrait dire que dans le cours d'une si longue et si orageuse révolution, ses opinions ont été non seulement conformes aux principes, mais applicables aux événements et aux circonstances, sans aucune teinte d'exagération, sans aucune aspérité, sans aucun mélange de faiblesse! Qu'il se nomme celui dont la conduite a été, nous ne dirons pas irréprochable et pure, car sans doute il en est beaucoup de tels, mais qui n'a beaucoup à regretter ou quelques excès d'un emportement excusable dans ces motifs, ou quelques ménagements qui soient dégénérés en mollesse, ou variations équivoques, ou des moments d'indécision, ou même d'une action nuisible aux progrès de la liberté ». Ceux, parmi les républicains, qui, prétendant être au-dessus de la multitude et à l'abri des imperfections, exigent toujours de frapper des peines de la loi tous les autres, les fautifs, rappellent Marat qui demandait deux cent mille têtes. Ils se parent de dehors d'une fausse justice, celle qui ne sait que punir et non pas pardonner.

La révolution a réveillé des passions fortes et a mis en branle d'immenses masses humaines. Comment donc poursuivre tout ceux qui ont participé à ses revirements et à ses égarements, « une foule prodigieuse d'hommes simples et de bonne foi qui furent des instruments passifs des chefs de diverses factions auxquelles ils se furent associés " ? Évitant soigneusement le terme de «terroriste ", désormais, après le 13 vendémiaire, banni du discours thermidorien, Baudin recourt aux périphrases et évoque le cas de "ceux-mêmes auxquels on attribue les premiers rôles et parmi lesquels on trouve des patriotes égarés qui crurent servir leur patrie ». Or, on a flétri avec éclat leurs fautes, jusqu'à oublier ce qu'ils avaient jusqu'alors de méritoire. Parmi eux se trouvent des « patriotes de 89 » qui, à l'heure de l'ultime danger, ont fait preuve de leur dévouement pour combattre la sédition du 13 vendémiaire. S'il faut traiter avec indulgence ceux qui, égarés, ont pris part à celle-ci, comment serait-on sévère à l'égard de ceux qui, dès son aurore, se sont déclarés pour la révolution? 
21 Faudrait-il donc laisser impunis les coupables des persécutions et des crimes commis à l'époque la plus sombre, celle de la Terreur? N'est-ce pas l'impunité des premiers coupables qui leur a donné des imitateurs ? Comment arrêter le cours des vengeances personnelles, sinon en livrant à la justice tous ceux contre lesquels tant de griefs se sont accumulés ? La justice ne doit-elle pas être toujours à l'ordre du jour, afin de punir les coupables et de réparer les torts? "Nous demanderons à ceux qui font ce raisonnement, s'il faut instituer autant de jurys qu'il y eut de comités révolutionnaires et couvrir la République de prisons et d'échafauds pour la consoler de tant d'échafauds et de prisons? Nous demanderons si, lorsqu'on aura frappé tous ceux qui sont réputés coupables, les malheurs de tant de familles aujourd'hui désolées seront réparés par d'autres malheurs, et si d'autres familles en désespoir ne viendront pas à leur tour pour obtenir du sang et des victimes? Nous demanderons si l'opinion publique est partout assez dégagée de préventions, si l'impartialité des juges est assez certaine pour qu'on puisse se promettre que la seule équité préside à toutes les décisions, pour qu'on soit assuré que le même accusé qui serait honorablement absous dans un tel tribunal, ne serait pas condamné dans tel autre ? (...) Toute violence amène une violence contraire, tout excès en provoque un autre, toute réaction (puisque ce mot nous a échappé) appelle une réaction, et de nouvelles recherches, de nouveaux jugements, de nouveaux supplices qui loin de mettre fin aux calamités passées ne seraient qu'un anneau de plus ajouté à une chaîne de désastres dont il deviendrait impossible de fixer le terme ». Il faut donc arrêter la spirale de vengeance et de violence. Il faut se rendre à l'évidence même si son goût est amer. «Il en est de maux inséparables d'une grande révolution, et parmi ces maux il en est qui, par leur nature, ne sont plus susceptibles de remèdes ».

Comment pourtant faire vivre ensemble les victimes et leurs bourreaux, les anciens prisonniers et leurs geôliers? Les familles des victimes et leur oppresseurs ? Comment faire confiance aux hommes qui, hier encore, ont combattu contre la liberté et persécuté des patriotes? Baudin ne se fait pas trop d'illusion sur la ténacité des haines et des fureurs accumulées pendant l'époque révolutionnaire; il ne croit guère à un nouveau "baiser de Lamourette", à un élan de générosité qui, soudainement, réconcilierait tout le monde, ferait pardonner les offenses et oublier les ressentiments. Il faut donc être réaliste et se résigner : dans l'état où se trouvent leurs passions aigries et déchaînées, les Français ne vont point s'aimer et longtemps resteront profondément divisés. Et pourtant, puisqu'ils sont condamnés à vivre ensemble, il faut qu'ils cessent de s'entretuer. "Même si vous ne pouvez vous résoudre encore à traiter vos concitoyens en frères, cessez au moins d'agir à leur égard en ennemis, s'il vous est impossible de les aimer, ne consentirez-vous pas au moins à ne plus les haïr, et si enfin cette haine continue d'être un besoin pour vous, est-ce trop attendre que de vous demander le désistement de tout projet de vengeance?».

Que deviendront pourtant la sûreté publique, la justice et la morale si, à la faveur de l'amnistie, les crimes restent impunis et les coupables échappent à leur châtiment ? Or, observe Baudin, il ne faut pas oublier que l'amnistie concerne uniquement les faits relatifs à la Révolution; par contre, les crimes et les délits de droit commun, "sans rapport avec les agitations politiques ", seront jugés selon toute la sévérité de la loi. D'autre part, c'est précisément la morale, la justice et la sûreté publique qui demandent impérativement de "substituer la clémence à la sévérité ». La raison d'État commande d'arrêter les interminables poursuites et les innombrables châtiments, car «il n'y a point de gouvernement qui puisse s'affermir par des barbaries dans un siècle des 
lumières ». La morale exige que l'on cesse d'irriter la soif du sang dans le cœur de la multitude: "l'habitude de le voir couler dégénère en un besoin atroce qui dégrade le peuple ». Quant à la justice dont on revendique les maximes inviolables, elle apprend que si, dans les temps ordinaires et sous un gouvernement paisible, la loi doit être appliquée sans ménagement, il n'en est pas de même dans les « discordes civiles et à la suite d'une longue agitation politique». Dans ce cas, il est juste de recourir à d'autres lois, analogues à celles de la guerre. En effet, il serait atroce que les vainqueurs, pour venger leurs victimes, immolent les ennemis vaincus désarmés ou captifs. De même les conquérants de la liberté ne peuvent, sans outrager la nature, se permettre des rigueurs à l'égard de ceux qui, désormais soumis au régime républicain, en auraient précédemment combattu l'établissement. «Beaucoup moins encore doit on punir les fautes des patriotes qui contribuèrent à la victoire et dont le zèle indiscret (sic!) leur fit souvent des ennemis ». À l'époque où la patrie était en danger «les recherches n'ont épargné personne, la défiance et le soupçon n'ont été retenus par aucune considération ». Mais les temps ont changé : "c'est de cette enceinte que doit partir le signal de la paix; et vainement essayeriez-vous d'en jeter les germes précieux dans le cœur des Français, si vous ne leur en donnez l'exemple salutaire. Soyons inexorables, quand il s'agit du salut de l'État, mais soyons justes, pour ne pas sacrifier aux soupçons ceux qui lui ont rendu des services incontestables".

Autant d'arguments en faveur d'un premier volet de la loi proposée : avec effet immédiat, sont abolis "tout décret d'accusation ou d'arrestation mis ou non à exécution, toutes procédures, poursuites ou jugements portant sur les faits purement relatifs à la Révolution "; par conséquent, "tous détenus à l'occasion de ces mêmes événements seront immédiatement élargis " À première vue, ces dispositions sont aussi radicales que spectaculaires; en réalité, elles consolident plus une situation déjà acquise qu'elles annoncent du neuf. En effet, Baudin les avaient conçues à l'époque où les prisons thermidoriennes regorgeaient encore d'anciens «terroristes »; or, au moment où il propose ces mesures à la Convention, les geôles, depuis une dizaine de jours, étaient déjà en train de se vider. On se souvient, en effet, que le 14 octobre, (22 vendémiaire), après l'écrasement de la rébellion parisienne, la Convention a décidé de libérer, dans les vingt-quatre heures, tous les "patriotes opprimés »; l'amnistie ferait donc consacrer solennellement cette mesure de clémence déjà ancienne. Baudin voudrait la faire étendre sur «tous les partis, pour les anéantir plus efficacement par oubli des torts, que par les persécutions qui perpétuent les sectes politiques aussi bien que les sectes religieuses». Cependant, dans sa version définitive, la loi décrétée comporte des réserves notables sur lesquelles nous aurons à revenir et qui limitent singulièrement sa portée.

Dans ce contexte, gagnait encore plus en importance le second volet de la loi proposée, à savoir l'abolition de la peine de mort. Couronnant ainsi son œuvre, insiste Baudin, la Convention affirmera la continuité de sa mission : à sa première séance, elle a aboli la royauté, régime tyrannique et anachronique, à sa dernière séance, elle abrogera un châtiment barbare. Mettre fin à la peine capitale sera un acte symbolique fort : au delà des années terribles de la Terreur, la République renouera ainsi avec ses origines intellectuelles et morales. À la pointe de son époque, de ce siècle éclairé, victorieuse de ses ennemis et de ses propres échecs, elle réunira pour toujours liberté et magnanimité. «Nous vous proposons, dit Baudin, au nom de l'humanité et de la philosophie l'abolition de cette peine qui répugne à la nature, qui multiplie la destruction de notre 
espèce d'une manière honteuse et barbare et qui fait succéder à la douleur publique causée par le crime le spectacle révoltant de la mort du coupable (...) Dans votre première séance vous avez rapidement aboli la royauté; dira-t-on sans examen? Quatorze siècles de notre histoire n'avaient-ils pas suffi pour instruire ce grand procès et vous qui deviez être les juges, vous auriez été suspects d'ignorance ou coupables de lenteur en différant le moment. Il en est de même pour l'abolition de la peine de mort. L'opinion est formée, les motifs sont connus depuis longtemps, les débats sont superflus pour préparer le décret qui doit à son tour illustrer votre dernière séance. Qu'entre ces deux abolitions se soient placés des événements tantôt glorieux et tantôt sinistres; que la censure comme l'admiration revendiquent la part que votre session fournit à l'un et à l'autre, croyez que ce début magnifique et cette immortelle clôture fourniront aux crayons de l'histoire des traits qui fixeront les regards de la postérité ».

Baudin ne se contente pas pourtant de proposer l'adoption d'un acte législatif. Conforme au code culturel de son temps il veut traduire le message véhiculé par la loi dans un langage des signes qui parle aux yeux, frappe l'imagination et émeut le cœur. Afin que cet acte assume la plénitude de ses fonctions symboliques et qu'il devienne un puissant instrument de la pédagogie civique, il faut reprendre l'exemple de grandes fêtes révolutionnaires. «Ce n'est pas assez que le décret d'abolition de la peine de mort soit prononcé dans cette enceinte, et qu'il soit le dernier de tous ceux qui auront été envoyés. Non loin du lieu de vos séances est une place qui n'en est séparée que par le Jardin national. Nous savons que le sang des coupables coula sur cette place, comme celui des innocents [...]. Que la Convention aille prononcer son décret sur la place de la Révolution; que le président y foule aux pieds la faux de la mort; qu'elle y soit brisée solennellement, et que ses débris soient déposés dans vos archives; que cette place porte aussitôt le nom de la place de la Concorde, et qu'un décret conserve le nom de la rue de la Révolution à celle qui le porte aujourd'hui, et qui conduit du boulevard sur la place. Puisse les Français en conclure, que la Révolution était un passage qui devait les conduire à la concorde, et qu'arrivés à ce terme désiré, l'immensité de l'espace offre de toutes parts à leur regards enchantés une perspective aussi riante qu'étendue ».

L'idée était sublime et l'image grandiose, digne du pinceau de David : au lever du soleil (naturellement!), sur le fond de l'immense place, sombre et hantée par des souvenirs terribles, se détache le groupe compact de conventionnels aux visages tirés par la fatigue, éclairé par le feu de l'échafaud incendié; par terre, sous l'éclat des premiers rayons du soleil, scintillent les fragments du couperet brisé... Cependant la Convention n'est pas allée à la place de la Révolution, son président n'a guère piétiné la « faux fatale ». Pour le faire, la Convention manqua matériellement de temps et, surtout, elle manqua de volonté politique.

La Convention a entamé le débat sur le rapport de Baudin le 3 brumaire (25 octobre). Une seule voix s'est élevée en faveur de l'abolition de la peine capitale et proposa même de faire brûler la guillotine: "Ce n'est pas une faux, c'est la guillotine qu'il faut détruire, cet instrument qui a fait périr tant d'innocents. Je demande que l'on brûle tout son échafaudage » (Philippe-Delleville). Elle fut cependant couverte par des cris La mort aux royalistes, tandis que de bruyants applaudissements des tribunes ont accueilli les réserves formulées par Reubell: «J'applaudis aux principes de philanthropie et d'humanité sur lesquels le rapporteur a basé le projet de décret, et certes il faut toute la gravité des circonstances où se trouve la République pour ne pas l'accepter à l'instant. Mais nous sommes forcés de l'ajourner encore [...] et je vous le demande, citoyens, si le 
décret qu'on vous propose, porté prématurément, ne serait pas l'arrêt de mort de tous les républicains ». La Convention décida donc d'ajourner le débat. Toutefois, en attendant, dans la foulée de la même séance, elle a décrété son ultime loi répressive frappant en particulier, les émigrés et leurs familles, comme si, d'avance, elle imposait des limites à l'éventuelle amnistie.

Le débat sur le rapport de Baudin n'a repris que le lendemain, le 4 brumaire (26 octobre), vers une heure de l'après-midi, c'est-à-dire au moment où l'horloge sonnait l'heure fatidique fixée par la loi comme terme du mandat de la Convention. Alors, avant que le président ouvre la discussion, dans la salle, des voix s'élèvent : Quelle heure est-il ?, auxquelles d'autres députés répliquent: L'heure de la justice; selon l'anecdote, pour sauver les apparences, le président aurait même fait arrêter la pendule. Seul MarieJoseph Chénier se prononça fermement en faveur de l'abolition immédiate et inconditionnelle de la peine capitale. «Ce n'est point ici d'examiner si jamais la peine de mort a pu être nécessaire, mais d'examiner d'abord si, dans notre situation, il n'est pas juste, il n'est pas instant d'en prononcer l'abolition. Je pense, moi, que rien n'est plus nécessaire, car si l'on s'en était avisé plutôt pendant la Révolution, nous aurions moins de talents à regretter, et l'on aurait épargné bien des crimes. La constitution étant établie, étant en pleine activité, vous devez ouvrir un vaste champ au repentir. Oui, vous devez ouvrir un vaste champ au repentir de ceux qui, dans le premier instant, se sont livrés aux mouvements impétueux des passions; eût plu au ciel qu'après le 31 mai ceux qui avaient demandé l'arrestation de nos malheureux collègues eussent eu le pouvoir de demander leur rentrée dans cette enceinte. Prenez garde, je vous supplie, que vous n'abolissez pas les passions; elles existent dans la nature de l'homme, et que, bien loin d'être pour elles un frein puissant, la peine de mort, pendant le temps et à la suite d'une révolution, devient leur arme la plus terrible, puisqu'elle passe entre les mains de tous les partis dont chacun immole successivement celui qu'il a renversé ». Cet appel au repentir ne fait provoquer que des murmures et des ricanements, du côté gauche. Par contre, des applaudissements nourris et des bravos partent de ce même côté ainsi que des tribunes lors de l'intervention de Reubell qui, énergiquement, réaffirme ses réserves de la veille. «En ce moment elle (l'abolition de la peine de mort) ne ferait qu'enhardir les conspirateurs. Voyez seulement depuis que la proposition vous en est faite, à quel point la jubilation éclate sur leurs visages. Nous pouvons conspirer, disent-ils; si nous ne sommes pas les plus forts, nous nous cacherons; si nous sommes pris, nous en serons quittes pour cinq années des fers, dont une nouvelle amnistie nous exemptera. Tels sont les dangers dont la liberté est menacée si vous abolissez la peine de mort. J'ajoute une petite considération: ce qu'il faudrait prier le royalisme d'avoir la bonté de l'abolir en notre faveur». Reubell propose donc d'ajourner l'abolition jusqu'à la paix générale. Baudin n'a défendu que mollement sa proposition initiale qui, insista-t-il, exprime surtout une position de principe: «La commission des Onze avait comme mission de proposer les principes dans toute leur pureté (...) La raison publique demandait l'abolition de la peine de mort comme celle de la royauté; c'étaient deux fléaux qui pesaient également sur l'humanité ». Ce principe admis, consent-il, il reste à constater que « tout contre-révolutionnaire est en état de guerre avec la société, qui peut faire ôter l'existence à celui qui a attenté à la sienne ». Il ne s'oppose donc pas à ce que la Convention accepte le principe d'abolition en reculant cependant son application à un moment plus opportun, celui de la paix générale. Finalement, accepté dans une version amendée, l'article premier de la loi stipule : « ̀̀ dater du jour de la publication de la paix générale, la peine de mort sera abolie dans 
toute la République française ». Dans la foulée, sans même en débattre, à l'unanimité, l'assemblée décréta l'article suivant : «La place de la Révolution portera désormais le nom de la place de la Concorde. La rue qui conduit du boulevard à cette place portera le nom de la rue de la Révolution ».

Le discours sur l'amnistie était plus généreux que l'amnistie elle-même. Dans sa version définitive la loi porte sur des «faits purement relatifs à la révolution». Tout décret d'accusation ou d'arrestation, tout mandat d'arrêt mis ou non à exécution, toute procédure portant sur ces faits sont immédiatement abolis et tous les détenus «à l'occasion de ces mêmes événements immédiatement libérés ». La loi comporte cependant de nombreuses restrictions qui limitent singulièrement la portée de cette disposition générale. Ainsi, se trouvent «formellement exclus de l'amnistie », ceux qui ont été condamnés par contumace "pour des faits de la conspiration de vendémiaire " (on se souvient que les tribunaux militaires ont condamné à mort par contumace une quarantaine d'hommes), ceux à l'égard de qui il y a une instruction ou des preuves relatives à cette même conspiration; les prêtres déportés ou sujets à la déportation, les émigrés rentrés ou non sur le territoire de la République. Finalement, l'amnistie profite donc surtout aux anciens «terroristes " au cas où ils n'étaient pas encore relâchés. Par contre, les grands perdants de l'amnistie sont les émigrés et leurs familles. L'amnistie non seulement n'abroge aucune mesure répressive à leur encontre mais le décret stipule explicitement que, dans aucun cas, l'amnistie ne déroge aux mesures de rigueur et d'exclusion décrétées la veille, le 3 brumaire.

C'était donc une vraie fausse abolition de la peine capitale. Au moment de la proclamation de la paix générale, en 1802, suite à la paix d'Amiens, personne ne se souviendra plus de cette loi de la Convention. Comme on le sait, il faudra attendre la Commune de Paris, en 1871, pour que la guillotine soit symboliquement brûlée, et ce n'est qu'en 1981 que la peine capitale a été effectivement abolie. De sorte que seule la nouvelle dénomination de la splendide place, ci-devant place de la Révolution, après avoir été auparavant place de Louis XV, garde encore aujourd'hui, au cœur de Paris, le souvenir de l'abolition avortée de la peine capitale en 1795 .

\section{ANNEXES}

\section{Rapport de Baudin 6}

BAUDIN (des Ardennes), au nom de la commission des Onze : Représentants du peuple, vous touchez au terme de vos travaux, et bientôt vous allez vous dessaisir des pouvoirs immenses dont vous étiez investis. Le moment est arrivé d'en faire, avant votre séparation, un usage qui vous console de ce que leur exercice a souvent eu d'indispensablement rigoureux. Il est enfin permis de laisser échapper ce mot que notre bouche retenait à regret, et sur lequel vos cœurs vous préviennent sans doute; mais, avant même de le prononcer, nous nous hâtons de rassurer ceux qui pourraient 
s'alarmer d'une interprétation dont il n'est point susceptible. Ce n'est point l'impunité $\mathrm{du}$ vol et du meurtre que nous vous demandons, lorsque nous venons vous proposer d'effacer, par une amnistie nécessaire, le souvenir des erreurs et des fautes qui ont été commises pendant la Révolution.

Rappelez-vous qu'à son origine, il n'est aucune des réformes qu'elle a depuis amenées, qui n'eût été provoquée par chacun de ceux qui ne profitaient point des abus dont le redressement n'ait excité des clameurs et occasionné des résistances.

Le magistrat s'était récrié contre l'opulence et les dérèglements du bénéficier; l'homme de guerre s'était plaint de la dispensation aussi lente que ruineuse de la justice; le négociant voulait qu'on mît fin aux usurpations féodales, et le ministre des autels qu'on arrêtât les déprédations du financier; chacun exerçait à l'envi la censure, et ne commençait à s'en plaindre qu'au moment où elle l'atteignait à son tour. Serait-il étonnant, d'après une telle expérience, que l'amnistie, au seul nom de laquelle tous les Français devraient tressaillir d'une commune joie, ne trouvât, dans des cœurs ulcérés, une opposition qui leur en fit repousser l'idée comme désastreuse ? Tous voudraient qu'on jetât un voile épais sur leurs propres torts, mais qu'il est rare de consentir à pardonner ceux des autres et d'être, à leur égard, disposé à l'indulgence dont on a besoin pour soi-même !

Chaque parti est prêt à la revendiquer exclusivement pour ceux qui lui furent attachés; comme dans le principe, chaque corporation prétendit échapper seule à des innovations qu'elle demandait à l'égard des autres.

Qu'il en soit du pardon comme de la réforme; qu'il embrasse tout, puisqu'elle a tout attaqué. Chacun voulut que la réforme n'épargnât que lui seul; chacun veut encore aujourd'hui que le pardon ne soit que pour lui. La maxime du législateur est que la loi doit être égale pour tous.

Qu'il s'avance, cet homme privilégié, citoyen ou magistrat, ou représentant du peuple, qui pourrait dire que, dans le cours d'une si longue et si orageuse révolution, ses opinions ont toujours été, non seulement conformes aux principes, mais applicables aux événements et aux circonstances, sans aucune teinte d'exagération, sans aucune aspérité, sans aucun mélange de faiblesse !

Qu'il se nomme celui dont la conduite a été, nous ne dirons pas irréprochable et pure, car sans doute il en est beaucoup de tels, mais qui n'ait point à regretter ou quelques excès d'un emportement excusable dans ses motifs, ou quelques ménagements qui soient dégénérés en mollesse, ou des variations équivoques; ou des moments d'indécision, ou même une inaction nuisible aux progrès de la liberté !

O vous, qui prétendez avoir suivi, sans en dévier un seul instant, la ligne d'un patriotisme irrépréhensible; vous, dont le courage ne s'est jamais ralenti, et dont la sagesse n'a pas été un seul instant en défaut, avancez dans cette enceinte; la nation va vous décerner des honneurs : mais avant de les recevoir, dites-nous encore, si c'est vous qui renouvellerez ici le vœu impie de Marat, lorsqu'il y demandait deux cent mille têtes.

Faut-il frapper, non pas du glaive de la mort, mais des peines de la loi, la multitude de ceux qui n'étant pas comme vous infaillibles et impeccables, n'ont pas su se préserver de quelques écarts! Ah! si vous prononcez leur condamnation, c'est en vain que vous vous parez des dehors d'une fausse justice. Elle n'est qu'un masque imposteur, puisque 
vous portez un cœur impitoyable; et, quand vous vous donnez pour exempts des imperfections de l'humanité, vous êtes dépourvus de l'une des vertus dont elle s'honore le plus, dès que vous ne savez point pardonner.

Que chacun descende dans son propre cœur, et bientôt il y puisera des motifs d'une clémence à laquelle tous ont également intérêt, car c'est de toutes les suppositions la plus fausse que celle par laquelle on a prétendu diviser la nation française en deux portions, celle des oppresseurs et celle des opprimés; cette doctrine conduirait, par un enchaînement de conséquences, à demander des châtiments et des supplices pour venger ceux sur qui pesa l'oppression, mais gardons-nous d'adopter une erreur aussi manifeste qu'elle est dangereuse, et voyons quelle a été la véritable situation de tout Français. Il n'en était aucun qui pût se dispenser de prendre part à la Révolution; ils ont dû se regarder tous dès le premier moment comme embarqués dans un même vaisseau; et devenus par nécessité matelots, soldats, ou tout au moins passagers, tous obligés par conséquent à prendre part à la manœuvre dans les tempêtes pour le salut commun, tous destinés à périr si chacun ne déployait contre les vents et les écueils tout ce qu'il avait de force et de courage, sans qu'il fût possible désormais ni de rétrograder vers le point du départ, ni de relâcher dans aucun port que celui de la liberté.

Qu'est-il arrivé cependant? Au lieu de ce zèle unanime qu'un prompt succès aurait couronné et qui eût prévenu tant de malheurs, de sacrifices et de regrets, combien n'at-on pas vu d'indifférence, combien n'a-t-on pas trouvé d'opposition! Vous êtes restés spectateurs tranquilles des événements auxquels vous deviez vous associer, vous avez craint de vous déclarer avant de savoir à qui demeurerait la victoire; vous avez voulu rester neutres; et vous vous plaignez d'avoir essuyé des persécutions ! Elles furent injustes, nous le déclarons hautement, nous les abhorrons comme vous; mais qu'aviezvous fait pour vous y soustraire ? Dans cette commotion universelle et rapide, donnée à un grand peuple qui s'élançait vers la liberté, vous songiez uniquement à vos intérêts domestiques, à votre fortune personnelle, à votre avancement, et vous vous étonnez qu'on ait commis des excès à votre égard! Et vous, qui résistiez, les uns à force ouverte et les autres par des pratiques secrètes aux progrès de la Révolution; qui, pour en arrêter le cours, avez épuisé vos trésors et déployé des talents, qui mettiez tout en usage pour la décrier; qui, n'ayant à lui opposer que des conseils, suggériez à la jeunesse de prendre contre elle des armes qui ne convenaient plus à votre âge, ou que votre sexe vous mettait hors d'état de porter, nous direz-vous aussi que vous fûtes opprimés, et que vous ne pouvez remettre les offenses qui vous ont été faites, quand la patrie consent à ne plus se souvenir qu'elle avait droit de vous compter parmi ses ennemis!

Mais vous qui l'avez constamment et fidèlement servie, et qui venez aussi mêler des plaintes trop fondées à des reproches qui le sont si peu; qu'avons-nous à vous répondre ! Voilà, dites-vous, nos titres, et ils sont incontestables; voyez les blessures que nous avons reçues dans les armées; considérez les services que nous avons rendus comme magistrats dans les fonctions publiques, calculez l'étendue de nos offrandes civiques, et leur disproportion avec notre modique fortune, et cependant nous fûmes dépouillés, avilis, proscrits! Ah! Citoyens, vous réunissez tous les caractères du patriotisme le plus pur, mais allez-vous ternir son éclat en parlant encore de vengeance ! Oui, tout nous engage à vous croire les plus solides appuis de la liberté, pourvu qu'à tous les sacrifices que vous avez faits pour elle, vous ajoutiez celui de votre 
ressentiment; montrez-vous généreux, et à ce prix seulement nous vous reconnaissons pour patriotes.

Mais quoi ! S'agit-il donc de calculer ici les réparations personnelles qu'auraient à prétendre des citoyens lésés, lorsque la majesté nationale violée, méconnue, outragée, veut bien condescendre à l'oubli de tant d'excès, et donner l'exemple de la clémence. Le peuple français tout entier s'était choisi des représentants, il les avait investis de la plénitude de sa puissance, à une époque où le pouvoir exécutif, précédemment constitué, se trouvait anéanti, et l'ennemi, maitre d'une partie de notre territoire.

La force des événements vous obligeait à vous saisir de toute l'autorité nationale, quand votre mission ne l'aurait pas placée dans vos mains. Non seulement vous étiez envoyés pour représenter le peuple français, comme le sera tout corps législatif qui vous succédera; vous étiez de plus un pouvoir en même temps constituant et directorial, et néanmoins dans le cours de cette mémorable session, la nation fut insultée trois fois en votre présence; que disons-nous insultée ! Trois fois on vous assiégea dans cette enceinte à main armée, et l'on essaya de dissoudre la Convention.

Le 2 juin 1793 fut la journée des factions.

Le $1^{\text {er }}$ prairial de l'an III fut la journée de l'anarchie.

Le 13 vendémiaire de l'an IV fut la journée du royalisme.

Il est utile de rapprocher ces trois attaques, de les comparer dans leurs effets; et de faire sentir par la grandeur de l'offense celle d'un pardon, auprès duquel nul autre pardon ne doit rien coûter à ceux qui semblent hésiter encore à l'accorder. Ces trois attentats eurent ceci de commun, que quoique le royalisme se soit montré plus à découvert lors du dernier, il eut dans tous les trois une influence active, parce qu'il est de tous vos ennemis le plus ardent et le plus irréconciliable, le plus intéressé à se saisir pour détruire la liberté, des passions ou des erreurs de ceux qui eurent le malheur de l'outrager; enfin parce qu'autant de fois qu'on voulut frapper la République dans ses fondateurs, et l'ensevelir avec eux dans un même tombeau, il est évident que, quelle que fût la main dans laquelle se trouvait placé le poignard, c'était toujours le royalisme qui l'avait fourni et qui dirigeait ses coups meurtriers.

$\mathrm{Au} 2$ juin, les factions se trouvèrent d'accord, et, de leur coalition, résulta le funeste succès qu'elles obtinrent, et dont les suites pesèrent quinze mois entiers sur la France jusqu'au réveil du 9 thermidor.

Au $1^{\mathrm{er}}$ prairial, l'anarchie balança trois jours les destinées de l'État, et fût comprimée le quatrième.

$\mathrm{Au} 13$ vendémiaire, le royalisme parut, et fut à l'instant foudroyé.

Le royalisme seul osa pousser l'agression jusqu'à ses derniers excès, engager un combat, et vous réduire à déployer la force. Depuis vingt-trois jours, vous n'opposiez à son insolence et à ses fureurs que le langage de la raison et des exhortations paternelles, il vous arracha, par l'indispensable nécessité de défendre contre lui la République, cette victoire qu'il vous eût été facile d'obtenir plus tôt, et dont vous aviez éloigné le moment, dans l'espoir qu'on vous dispenserait d'obtenir, par la force, ce que la persuasion aurait dû produire.

Révoque-t-on en doute que ces trois fameuses attaques n'aient été les plus grands attentats qu'il fût possible de commettre contre la nation, à laquelle on voulait donner 
des fers autant de fois qu'on essaya d'anéantir sa représentation; et cependant qui se résoudrait à demander la poursuite, non seulement de la multitude innombrable de ceux qui prirent part aux journées du 2 juin, $1^{\text {er }}$ prairial et 13 vendémiaire, mais la punition de tous ceux qu'on a regardés comme coupables, surtout dans les deux premières! Aujourd'hui que nous regardons ces époques reculées avec le calme auquel le temps nous a ramenés, pourrions-nous contester, qu'indépendamment de cette foule prodigieuse d'hommes simples et de bonne foi qui furent des instruments passifs, il ne se trouvât parmi ceux-mêmes auxquels on attribue les premiers rôles, des patriotes égarés qui crurent servir leur patrie!

Leurs fautes furent relevées avec éclat, et non seulement on oublia ce qu'ils avaient fait jusqu'alors de méritoire; mais on n'a pas su que jusque dans leur emportement ils avaient résisté au vœu sanguinaire des chefs des factions, auxquels ils se trouvaient associés sans en avoir pénétré les desseins ultérieurs.

Qu'on se rappelle, en un mot, que le sang ne coula pas alors, et que les royalistes n'ont pas hésité de le répandre les premiers dans la sédition du 13 vendémiaire; et s'il faut traiter ces derniers même avec indulgence, comment serait-on sévère à l'égard des autres qu'on retrouve parmi ceux qui, dès l'aurore de la Révolution, s'étaient déclarés pour elle!

Mais, dira-t-on, n'est-ce pas l'impunité des premiers coupables qui leur a donné des imitateurs? et peut-on mettre un frein aux crimes; peut-on même arrêter le cours des vengeances personnelles, qu'en livrant aux poursuites de la justice tous ceux contre lesquels sont accumulés tant de reproches? Nous demanderons à ceux qui font ce raisonnement, s'il faut instituer autant de jurys qu'il y eut de comités révolutionnaires, et couvrir la République de prisons et d'échafauds pour la consoler de tant d'échafauds et de prisons? Nous demanderons si, lorsqu'on aura frappé tous ceux qui sont réputés coupables, les malheurs de tant de familles aujourd'hui désolées seront réparés par d'autres malheurs, et si d'autres familles au désespoir ne viendront pas encore à leur tour pour obtenir du sang et des victimes? Nous demanderons si l'opinion publique est partout assez dégagée de préventions, si l'impartialité des juges est assez certaine pour qu'on puisse se promettre que la seule équité préside à toutes les décisions, pour qu'on soit assuré que le même accusé qui serait honorablement absous dans un tel tribunal, ne serait pas condamné avec indignation dans tel autre ? L'expérience ne nous a-t-elle pas appris le danger des vicissitudes, ne savons-nous pas que ce n'est qu'après avoir parcouru les extrêmes qu'on s'arrête dans un juste milieu ? Combien de fois s'est-on plaint, avec fondement, que le gouvernement s'était relâché; que le choix des fonctionnaires publics avait été fait sans discernement, pour ne rien dire de plus; que des conspirateurs avaient été rendus à la liberté.

D’où sont nés ces abus, sinon des abus précédents ? La tyrannie avait encombré sans choix les prisons; elles furent ouvertes sans distinction, le gouvernement avait été féroce, il devint faible. Mais il faut le dire avec courage, l'immortelle révolution du 9 thermidor n'aurait jamais été poussée trop loin, si son juste développement n'eût éprouvé une résistance qui força d'aller au delà du but pour l'atteindre, et s'il n'eût fallu briser avec effort dans la main du second triumvirat le sceptre des premiers triumvirs dont il voulait se ressaisir, après avoir concouru, comme vous, à le leur arracher. 
Toute violence amène une violence contraire, tout excès en provoque un autre, toute réaction (puisque ce mot nous est échappé) appelle une réaction, et de nouvelles recherches, de nouveaux jugements, de nouveaux supplices, loin de mettre fin aux calamités passées, ne seraient qu'un anneau de plus ajouté à une chaîne de désastres dont il deviendrait impossible de fixer le terme.

Vous en sentez la raison, représentants du peuple. Il est des maux inséparables d'une grande révolution, et parmi ces maux, il en est qui, par leur nature, ne sont plus susceptibles de remèdes. Loin de les aggraver par des maux semblables qui ne seraient au fond que d'horribles représailles, tous vos efforts doivent se diriger à éteindre, à calmer du moins, ou enfin, si l'on ne peut mieux faire, à comprimer dans leurs effets les passions aigries qui n'implorent le nom sacré de justice que pour assouvir leur ressentiment.

Eh quoi donc ! Nous dira-t-on, faudra-t-il prodiguer les témoignages de l'amitié, de l'estime et de la bienveillance à des hommes qui nous ont traités avec une rigueur inouïe ? Serons-nous réduits à donner notre confiance à ceux qui sous nos yeux ont combattu contre la liberté et qui ont lâchement abandonné sa cause après l'avoir servie, ou qui sont restés à son égard dans une coupable indifférence? Non, sans doute, nous ne vous proposerons pas ces embrassements irréfléchis qu'un moment d'enthousiasme a quelquefois produits, et auxquels ont survécu les divisions; nous n'avons garde de vous engager à des démonstrations perfides que le cœur désavouerait et qui sont mille fois plus odieuses que les fureurs d'une inimitié franche et déclarée; mais si vous ne pouvez vous résoudre encore à traiter vos concitoyens en frères, cessez du moins d'agir à leur égard en ennemis; s'il vous est impossible de les aimer, ne consentirez-vous pas à ne plus les haïr, et si enfin la haine continue d'être un besoin pour vous, est-ce trop attendre que de vous demander le désistement de tout projet de vengeance ? Si vous n'êtes pas dignes de poser une pierre dans la construction de l'autel de la concorde, laissez-le du moins s'élever, et bornez-vous à ne pas vous opposer aux travaux de ceux qui, pour l'achever, sont résolus de prodiguer leurs sueurs, et s'il le faut de le cimenter de leur sang.

Mais que deviendront les intérêts de la société, ceux de la sûreté publique, ceux de la morale, ceux de la justice ! Loin de nous la pensée de compromettre de tels intérêts ou d'affaiblir le respect qui leur est dû.

Nous nous sommes empressés d'annoncer d'abord qu'il ne s'agissait point de soustraire aux poursuites de la loi ceux qui sont souillés des crimes qu'elle a prévus et dont elle prononce le châtiment dans tous les temps et sans rapport aux agitations politiques qui nous ont divisés. Qu'on demande compte à l'assassin du sang qu'il a versé, ce n'est pas nous qui prendrons ici sa défense; que l'usurpateur ne jouisse pas impunément de la fortune de celui qu'il a dépouillé; mais quand on parle de la sûreté publique, de la morale, de la justice, c'est en leur nom que nous demandons aussi de substituer la clémence à la sévérité.

Voyez quel fut dans tous les temps le résultat des rigueurs employées par les tyrans; une conspiration venait-elle à éclater, des supplices l'avaient-ils réprimée, une conspiration nouvelle se tramait, des échafauds étaient encore dressés, et leur aspect, destiné à imprimer la terreur, faisait éclore d'autres projets de résistance, et pâlir encore ceux contre lesquels ils étaient dirigés. 
Il n'y a point de gouvernement qui puisse s'affermir par des barbaries dans un siècle de lumières, et par conséquent point de sûreté publique à se promettre d'un système de cruauté.

L'exemple de Robespierre doit seul vous en convaincre, et certes l'esprit humain a fait assez de progrès depuis le temps de Sylla et du triumvir Octave, pour que les fondateurs de la République française ne veuillent pas se montrer inférieurs en humanité et en politique à ces deux hommes qui, moins lassés de proscriptions que convaincus de leur inutilité, n'attendaient plus leur propre salut ni celui de l'État que de la cessation des mesures sanguinaires.

Quel défenseur de la morale pourrait méconnaître que c'est lui faire l'outrage le plus cruel et lui porter la plus mortelle atteinte que d'irriter la soif du sang dans le cœur de la multitude, de vaincre en elle l'horreur naturelle qu'inspire son effusion par l'habitude de le voir couler, jusqu'à ce qu'enfin cette habitude dégénère en un besoin affreux qui dégrade le peuple et lui donne un caractère de férocité. Voyez les Orientaux abrutis par le despotisme, insensibles à leur avilissement; courbés sous un joug de fer, au lieu de briser la chaîne qui les accable; ils demandent, à grands cris, au sultan la tête des visirs; et cet horrible présent accordé sans hésiter, sert à perpétuer l'esclavage de ceux qui l'obtiennent, parce que l'outrage fait aux mœurs publiques tourne au profit de la puissance du despote.

Enfin, la justice dont on revendique les maximes inviolables nous apprend que si dans les temps ordinaires et sous un gouvernement paisible, les peines de la loi doivent être appliquées sans ménagement, il n'en est pas ainsi dans les discordes civiles et la suite d'une longue agitation politique.

Il est juste alors de recourir à d'autres lois, qui sont celles de la guerre; et comme après la victoire il serait atroce de compter le nombre des morts pour immoler autant de vaincus désarmés ou captifs qu'on aurait perdu de guerriers parmi les vainqueurs, et d'ordonner de sang-froid des blessures pour venger celles qui ont été reçues dans la mêlée, n'est-il pas évident que les conquérants de la liberté ne peuvent, sans outrager la nature, se permettre des rigueurs à l'égard de ceux qui, désormais soumis au régime républicain, en auraient précédemment traversé l'établissement ? Beaucoup moins encore doit-on punir les fautes des patriotes qui contribuèrent à la victoire, et dont le zèle indiscret lui fit souvent des ennemis.

Mais vous qu'on a vus fuir, dès l'aurore de la liberté, comme les ombres disparaissent aux premiers rayons du jour; vous qui êtes allés nous susciter des ennemis au dehors, ou qui, devenus nos ennemis les plus cruels, avez armé vos mains parricides d'un fer impie, vous encore, qui traînez de contrée en contrée la honte de votre fol orgueil, et pour qui vos compatriotes devinrent étrangers dès qu'ils reprirent à votre égard les droits de l'égalité qu'ils tenaient de la nature; vous enfin qui n'avez voulu partager ni nos périls, ni nos travaux, et qui ne combattez pour personne, mais qu'on eût vus recueillir paisiblement les fruits de l'odieuse victoire qui nous eût asservis, n'espérez pas que la patrie, dont vous avez méprisé la voix quand elle vous rappelait dans son sein, consente à vous y recevoir jamais. Vous avez rompu le pacte social. Fuyez toujours cette terre natale dont vous avez méconnu les droits, et si vous y osez porter un pied téméraire, sachez qu'elle s'ouvrira sous vos pas aussitôt pour vous engloutir. Ce n'est pas pour vous que nous réclamons aucune part à l'indulgence nationale. Vous n'avez rien non plus à y prétendre, vous qui venez de vous soustraire par la fuite aux 
jugements qui ont frappé les conspirateurs du 13 vendémiaire, ni vous qui, ministres d'un Dieu de paix, n'avez usé de la confiance que vous accordaient les citoyens que pour semer la discorde et la révolte.

Dans tous ce que nous vous proposons jusqu'ici, représentants du peuple, vous nous avez déjà prévenus par votre décret du 22 vendémiaire qui prononce la nullité de tous les actes d'accusation non motivés sur des délits que le Code pénal n'aurait pas prévus, ce qui rend la liberté à tous ceux qui se trouvaient détenus pour des motifs étrangers à ces délits.

Vous avez prétendu venir au secours des patriotes opprimés qui ne pouvaient avoir parmi vous un seul adversaire, en même temps que vous avez laissé à la justice son cours ordinaire contre les scélérats qui ne pouvaient trouver ici non plus un seul défenseur : mais vous ne voudrez pas en demeurer là : les patriotes méritaient de fixer vos premiers regards : la bienfaisance de la loi doit s'étendre aujourd'hui sur tous les partis, pour les anéantir plus efficacement, par l'oubli des torts, que par les persécutions que perpétuent les sectes politiques aussi bien que les sectes religieuses.

Mais, nous oserons vous le dire, représentants du peuple, c'est de cette enceinte que doit partir le signal de paix; et vainement essayeriez-vous d'en jeter les germes précieux dans le cœur des Français, si vous ne leur en donnez l'exemple salutaire.

Que dans les dangers de la patrie, qu'au sein des conspirations, les recherches n'aient épargné personne; que la défiance et le soupçon n'aient été retenus par aucune considération et par aucun ménagement, ceux mêmes qu'on aurait injustement accusés doivent encore applaudir au zèle inquiet qui ne veut épargner aucun coupable, ni rien dissimuler de ce qui conduirait à les découvrir. Jusque-là, l'inflexibilité républicaine a droit de manifester ses inquiétudes; mais l'équité doit les apprécier ensuite, peser les preuves, et rapprocher les inculpations de la doctrine qu'ont professée ceux qu'on a cru devoir attaquer, de leur conduite dans les occasions d'éclat, et de l'intérêt qu'ils peuvent avoir à soutenir leur réputation, comme à défendre leur vie qu'ils ont euxmêmes liée au sort de la République.

Le courage qui se signala par l'attaque décisive du 9 thermidor; la gloire qui résulte de l'expédition de Quiberon, l'intrépidité du $1^{\mathrm{er}}$ prairial, la fermeté du 31 mai, la constance dans les proscriptions qui le suivirent, se placent sur la même ligne dans les fastes de la Révolution. Les traits honorables qu'a publiés la renommée lui appartiennent désormais; et Scipion répondait à ses accusateurs en leur proposant d'aller au Capitole rendre grâces aux dieux, de la victoire par laquelle il avait immortalisé son nom.

Cette fierté n'est-elle pas une vertu qui convient au républicain autant que la vigilance de Cicéron, qui n'accusait les conspirateurs qu'en les accablant à la fois de la force des preuves comme de celle de son éloquence ? Et si Manlius, malgré ses victoires, fut précipité de la roche Tarpéienne, ce n'était aussi qu'après avoir été convaincu de crime.

Soyons inexorables, quand il s'agit du salut de l'État, mais soyons justes, pour ne pas sacrifier à des soupçons ceux qui lui ont rendu des services incontestables.

Quel caractère de réprobation plus frappant contre le royalisme, que le mépris opposé par la Convention nationale aux injures qu'il a vomies contre elle, et que le funeste effet des éloges perfides, qui, distribués par elle, suffisent pour inspirer contre ceux qui ont le malheur d'en être l'objet, des préventions et des défiances ! 
L'audace effrénée du royaliste dans la dernière attaque qu'il nous a livrée le 13 vendémiaire, nous a forcés de différer jusqu'à ce moment à vous proposer, au nom de l'humanité et de la philosophie, l'abolition de cette peine qui répugne à la nature, qui multiplie la destruction de notre espèce d'une manière honteuse et barbare, et qui fait succéder à la douleur publique causée par le crime le spectacle révoltant de la mort du coupable. En vain allègue-t-on pour le maintien de cette coutume atroce la nécessité de l'exemple, puisque d'autres nations ont bien su s'affranchir de ce remède affreux sans que les délits soumis à la peine capitale y soient devenus plus communs. On pourrait accumuler à l'infini les preuves qui doivent vous conduire à prononcer une suspension si nécessaire; les philosophes et les jurisconsultes nous en fourniraient un grand nombre, et nul sujet n'a prêté davantage à l'éloigner des écrivains sensibles qui l'ont traitée, mais ce serait insulter à la raison publique et aux lumières du siècle, que de rebattre ici des arguments devenus familiers; nous rougirions de nous appesantir sur cette question, comme vous auriez eu honte de discuter vous-même celle de la préférence de la République sur la monarchie. Dans votre première séance vous avez rapidement aboli la royauté; dira-t-on sans examen? Quatorze siècles de notre histoire n'avaient-ils pas suffi pour instruire ce grand procès, et vous qui deviez être les juges, vous auriez été suspects d'ignorance ou coupables de lenteur en différant un moment? Il en est de même pour l'abolition de la peine de mort.

L'opinion est formée, les motifs sont connus depuis longtemps, les débats sont superflus pour préparer le décret qui doit à son tour illustrer votre dernière séance.

Qu'entre ces deux abolitions se soient placés des événements tantôt glorieux et tantôt sinistres; que la censure comme l'admiration revendiquent la part que votre session fournit à l'un et à l'autre, croyez que ce début magnifique et cette immortelle clôture fourniront aux crayons de l'histoire des traits qui fixeront les regards de la postérité.

On a proposé, nous le savons, et l'on vous proposera de nouveau quelques exceptions à la loi que nous sollicitons; les crimes contre la sûreté de l'État paraissent à quelques personnes exiger que la crainte de la mort soit un frein qui retienne les conspirateurs. Nous partageons l'estimable sollicitude de ceux qui se montrent comme nous le sommes nous-mêmes jaloux de la sûreté publique, et nous ne partageons pas moins l'horreur que leur inspire l'énormité du crime, contre lequel ils veulent maintenir une peine qui lui soit uniquement applicable; mais nous répondrons que le mépris de la vie entre naturellement dans les calculs de quiconque se mêle de conspiration, que celui qui ne sait pas braver la mort, n'a pas cette énergie, cette audace du crime sans laquelle il n'y a point de conjurés, et qu'on n'a rien à se promettre à l'égard de cette espèce de criminels, de l'impression d'une crainte qu'ils ont d'avance surmontée.

Nous ajouterons surtout que conserver des échafauds, même pour un seul délit, c'est risquer qu'on en étende bientôt l'usage à des délits qui ne paraîtront pas moins odieux, ou qui, devenant communs dans certaines circonstances, sembleront exiger qu'on les réprime avec plus de force. En un mot, si l'on compose avec le principe, si l'on ne ferme pas l'abîme, il peut engloutir et dévorer encore ces victimes innocentes à l'égard desquelles les méprises des tribunaux sont quelquefois inévitables, même après avoir perfectionné l'instruction criminelle par l'institution sublime du jury. Quand il s'agit de laisser subsister une peine dont l'application est irréparable, quel législateur ne frémirait pas de penser qu'il se rend responsable de la prévarication ou de l'ignorance de tout juré qui fera périr un innocent. 
L'on osa dire à cette tribune que ceux-là seuls voulaient briser les échafauds, qui craignent d'y monter.

L'homme de bien sait qu'on y traîna Vergniaux, Barnevelt et Sidney, et quiconque est pénétré de l'indignation que doit allumer un tel souvenir, s'empressera de prévenir le retour de pareils forfaits.

Ici, représentants du peuple, il faut parler aux yeux, à l'imagination, surtout au cœur. Ce n'est point assez que le décret d'abolition de la peine de mort soit prononcé dans cette enceinte, et qu'il soit le dernier de tous ceux qui auront été envoyés. Non loin du lieu de vos séances est une place qui n'en est séparée que par le Jardin national. Nous savons que le sang des coupables coula sur cette place, comme celui des innocents : mais la Bastille avait aussi renfermé quelques criminels parmi les victimes du despotisme, et ceux qui renversèrent cet affreux château ne devinrent pas apparemment complices des scélérats qui avaient habité quelques-uns de ses cachots.

Que la Convention aille prononcer son décret sur la place de la Révolution; que le président y foule aux pieds la faux de la mort; qu'elle y soit brisée solennellement, et que ses débris soient déposés dans vos archives; que cette place porte aussitôt le nom de place de la Concorde, et qu'un décret conserve le nom de rue de la Révolution à celle qui le porte aujourd'hui, et qui conduit du boulevard sur la place. Puissent les Français en conclure, que la révolution était un passage qui devait les conduire à la concorde, et qu'arrivés à ce terme désiré, l'immensité de l'espace offre de toutes parts à leurs regards enchantés une perspective aussi riante qu'étendue !

Tel est, citoyens représentants, le dernier tribut de zèle et de travail par lequel votre commission s'efforcera de justifier votre confiance. Nous nous permettrons de vous rappeler que votre commission osa présumer assez de votre courage pour prendre sur elle l'initiative d'une constitution. Elle supposa votre vœu, sans être effrayée d'aucun autre danger que de celui de laisser la France livrée au système d'anarchie qui la dévorait.

L'ouvrage que nous vous avions soumis, vous l'avez perfectionné par une discussion également libre et sage; vous l'avez adopté, vous l'avez présenté à la nation; et son suffrage, que ni la corruption, ni la terreur n'ont influencé, vient d'en faire la loi fondamentale de la République. Nous ne nous sommes pas bornés à vous offrir la constitution; nous avons cherché les moyens qui nous ont paru les plus propres à la mettre en activité, comme à la garantir contre les efforts que ses ennemis feraient pour la renverser au moment même de son établissement.

Ce n'est pas seulement votre approbation, c'est l'acceptation du peuple, c'est encore le déchaînement du royalisme qui nous ont prouvé que votre commission ne s'était pas trompée dans le choix des moyens sur lesquels son vœu a été unanime. Elle doit à la Convention nationale, elle doit à la République, de vous déclarer solennellement qu'elle ne croit point la Révolution terminée sans une amnistie : c'est à vous de prononcer ensuite dans votre sagesse; mais en vous remettant nos pouvoirs, le dernier usage que nous allons en faire est de nous acquitter de ce que nous prescrit notre conscience; c'est elle qui nous pressa de travailler au plan d'une véritable constitution; c'est elle encore qui nous oblige de vous dire qu'aucun gouvernement ne s'établit sans l'oubli des fautes et des erreurs qui ont précédé et même troublé ou retardé sa formation.

L'assemblée donne des applaudissements au rapport et à plusieurs articles du projet. 


\section{Loi d'amnistie : 4 brumaire an IV}

Art. I. À dater du jour de la publication de la paix générale, la peine de mort sera abolie dans toute la République française.

II. La place de la Révolution portera désormais le nom de place de la Concorde. La rue qui conduit du boulevard à cette place portera le nom de la rue de la Révolution.

III. La Convention abolit, à compter de ce jour, tout décret d'accusation, tout mandat d'arrêt mis ou non à exécution, toutes procédures, poursuites et jugements portant sur des faits purement relatifs à Révolution. Tous détenus à l'occasion de ces mêmes événements seront immédiatement élargis, s'il n'existe point contre eux de charges relatives à la conspiration du 13 vendémiaire dernier.

IV. Les délits commis pendant la Révolution, et prévus par le code pénal, seront punis de la peine qui se trouve prononcée contre chacun d'eux.

V. Dans toute accusation mixte, où il s'agirait à la fois des faits relatifs à la Révolution et de délits prévus par le code pénal, l'instruction et le jugement ne porteront que sur les ces délits seuls.

VI. Tous ceux qui sont ou seront accusés de dilapidation de la fortune publique, concussions, taxes et levées de deniers avec retenue de tout et partie au profit de ceux qui les auront imposés, ou de tout autre fait semblable survenu pendant et à l'occasion de la Révolution, pourront être poursuivis, soit au nom de la nation, soit par les citoyens qui prouveront qu'ils ont été lésés; mais les poursuites se feront seulement par action civile et à fin de restitution, sans aucune autre peine.

VII. Le Directoire exécutif pourra différer la publication de la présente loi dans les départements insurgés par des troubles, à la charge de rendre compte au Corps législatif, tant du nombre de départements où la publication sera suspendue, que du moment où elle y sera faite, aussitôt que les circonstances le permettront.

VIII. Sont formellement exceptés de l'amnistie :

$1^{\circ}$. Ceux qui ont été condamnés par contumace pour les faits de la conspiration de vendémiaire.

$2^{\circ}$ Ceux à l'égard desquels il y a une instruction commencée ou des preuves acquises relativement à la même conspiration, ou contre lesquels il en sera acquise par la suite; $3^{\circ}$ Les prêtres déportés ou sujets à la déportation;

$4^{\circ}$ Les fabricateurs de faux assignats ou de fausse monnaie;

$5^{\circ}$ Les émigrés rentrés ou non sur le territoire de la République.

IX. Il n'est dérogé par la présente loi à aucune des dispositions de celle du 3 de ce mois.

\section{NOTES}

2. Rappelons que, selon les estimations, le nombre d'électeurs s'élevait à environ 5 millions et qu'en 1793 le plébiscite sur la constitution montagnarde a donné 1714266 oui et environ 12000 non.

3. Las Cases, Mémorial de Sainte Hélène, coll. Intégrale, Seuil, Paris, 1968, p. 112. 
4. Pierre-Charles-Louis Baudin (dit des Ardennes), né en 1748, à Sedan, débute sa carrière au barreau de Sedan, ensuite devient précepteur des enfants du président du parlement, Gilbert des Voisins; en 1786, il obtient l'emploi du directeur des postes à Sedan. Nommé maire de Sedan en 1790, il est élu député des Ardennes à l'Assemblée législative, où il fait partie du Comité d'instruction publique. Réélu à la Convention, il fait partie de la Commission des archives; modéré, proche des Girondins, lors du procès de Louis XVI, il vote pour l'appel au peuple, pour le bannissement jusqu'à la paix et pour le sursis; le 13 avril 1793, il vote pour la mise en accusation de Marat; pendant la Terreur il se tait, se cantonne dans ses fonctions à la Commission des archives et échappe aux persécutions. Après le 9 thermidor, il prend parti contre les jacobins et les députés montagnards; élu à la commission des Onze, ses activités, que nous évoquons dans le texte, lui assurent ses heures de gloire. En 1795, il est élu au Conseil des Anciens, qu'il préside à deux reprises, en 1795 et en 1798, et où il est maintenu commissaire aux archives. En 1797, il se range du côté du Directoire et soutient le coup d'État du 18 fructidor; pendant la crise de l'été 1798, il appuie le Directoire, critique les néo-jacobins; de plus en plus déçu par le régime directorial, il se rapproche de Sieyès. Il meurt subitement, le 14 octobre 1799; il aurait succombé à une crise cardiaque provoquée par la joie qu'il éprouva en apprenant l'arrivée de Bonaparte en France. Membre de l'Institut, entre 1795 et 1799, il publie quelques écrits politiques. Connu pour ses mœurs austères (il se déclarait lui-même janséniste), et pour sa vaste culture, après thermidor, Baudin a acquis un grand prestige politique et intellectuel. En 1795, il collabore à la Sentinelle de Louvet; Benjamin Constant l'a connu à cette occasion; par la suite, il l'a beaucoup fréquenté et lui consacra une notice nécrologique. «Baudin avait acquis, sur ses amis et sur ses collègues, l'ascendant de la raison la plus éclairée et de la moralité la plus profonde (...) Baudin possédait des connaissances positives très étendues, avantage précieux à l'époque où nous nous trouvons (...) Mais ce n'est pas simplement comme homme public que Baudin est regrettable. Quiconque l'a connu dans l'intimité ne put s'empêcher de donner à sa perte des larmes amères. L'on ne sortait jamais de chez lui sans se sentir affermi et par son exemple, et par ses discours, dans ses habitudes d'intégrité, de rectitude, de moralité républicaine. L'on voyait en lui la vertu simple, active, courageuse, s'appuyant, il est vrai, sur des idées religieuses, mais qui donc, même en ne les partageant pas, pourrait ne pas les lui envier ? On le quittait plus satisfait de soi-même et de lui, moins honteux de l'espèce humaine, espérant mieux de la liberté » $\mathrm{B}$. Constant, Écrits de jeunesse (1774-1795), textes établis et annotés par M. Barberis, Tübingen, 1998, pp. 688-689. Dans sa brochure De la force du gouvernement actuel... (1796) Constant a fait siennes plusieurs idée formulées par Baudin dans ses rapports d'août 1795.

5. Dans la suite je cite le rapport de Baudin et les débats qui l'ont suivi selon Le Moniteur, réimpression, Paris, 1862, t. 26, pp. 301-307; 346-349.

6. Texte saisi et mis en forme par Céline Mangeat (Université de Genève, mémorante en histoire moderne).

\section{RÉSUMÉS}

Le 26 octobre 1795 (4 brumaire an IV), la Convention nationale proclame l'amnistie pour «les faits purement relatifs à la révolution ». Acte solennel par lequel la Convention achève sa mission, cette amnistie se présente sous un triple aspect: d'une part, elle est l'aboutissement d'un projet politique, celui de terminer la Révolution; d'autre part, elle est le produit des circonstances, en particulier, de l'écrasement sanglant de l'insurrection parisienne encadrée par 
des royalistes (5 octobre 1795, 13 vendémiaire an IV); finalement, elle est l'œuvre d'un homme, P.C.L. Baudin, conventionnel, député des Ardennes. Imaginée comme acte symbolique fort, l'amnistie est également pensée comme mesure politique indispensable: abolissant la peine capitale et vidant les prisons, elle tournerait la page à la fois de la Terreur et de la répression anti-terroriste. Toutefois la rhétorique thermidorienne s'est avérée plus généreuse que l'acte même de l'amnistie. On trouvera le rapport de Baudin à la Convention en annexe de l'article.

On 26 October 1795 (4 Brumaire, Year IV), the National Convention proclaimed an amnesty for "acts strictly related to the revolution". This amnesty - a solemn decision by which the Convention put an end to its mission - had three key elements : first, it achieved the political project of terminating the Revolution; second, it was a product of circumstances, in particular, the bloody crackdown of the royalist revolt in Paris on 5 October 1795 (13 Vendémiaire, year IV); and finally, it was the work of a single member of the Convention, the deputy of the Ardennes, P.C.L. Baudin. Conceived as a strong symbolic act, this amnesty was also designed to be a significant political move : by abolishing capital punishment and emptying the prisons, it was expected simultaneously to bring an end to both the Terror and anti-terrorist repression. Thermidorian rhetoric, however, proved more generous than the actual amnesty. Baudin's report to the Convention is appended to the article.

\section{AUTEUR}

\section{BRONISLAW BACZKO}

Université de Genève, 10 Av. du Lignon, CH1219-Genève, baczko@bluewin.ch Bronislaw Baczko est professeur honoraire à la Faculté des Lettres de l'Université de Genève. Il a publié notamment : Comment sortir de la Terreur. Thermidor et la Révolution, Paris, Gallimard, 1989; Job mon ami. Promesses du bonheur, fatalité du mal, Gallimard, 1997; Lumières de l'utopie, nouv. édition, Paris, Payot, 2001. Le sujet de ses recherches actuelles est « Entre Thermidor et Brumaire : culture et politique ». 